\title{
Флорариумы. Жизнь и развитие растений в стеклянных емкостях
}

\author{
Окружающий мир
}

\author{
Штайда К.П. \\ 4 класс, СОШ №4, г. Солигорск \\ Научный руководитель: Аричименя О.Л., учитель начальных классов, \\ СОШ №4, г. Солигорск
}

\section{Введение}

Использование комнатных растений является одним из доступных и распространенных вариантов украшения квартир, школьных классов, домов и других помещений. Цветы очищают воздух от вредных примесей, положительно влияют на здоровье человека, помогают справиться со стрессом.

Я люблю ухаживать за комнатными растениями, наблюдать за их развитием. Но в жизни не всегда удается уделить им достаточного количества времени. Да и многие из них прихотливы и требовательны в уходе, а другим совершенно не подходит климат закрытых помещений.

Также я заметил, что цветочные горшки занимают много места в квартире, их невозможно разместить на узких поверхностях. А небольшие растения поодиночке смотрятся некрасиво и негармонично.

Из журнала по цветоводству «Удивительный сад в бутылке» я узнал о существовании флорариумов. Это разнообразные по форме и размеру сосуды из стекла или прозрачного пластика, в которые высаживают комнатные цветы. Растения в них не требуют ухода, либо уход осуществляется минимальный. Но в нашем городе флорариумов нет в продаже, а в интернет - магазинах они стоят дорого. Поэтому я решил поэкспериментировать и сделать их самостоятельно из различных стеклянных предметов. 
Данной работой я хочу показать, что привычный способ выращивания комнатных цветов в горшках можно заменить более простым в уходе и оригинальным - созданием флорариумов.

Цель: определение возможности выращивания комнатных растений в стеклянных емкостях.

\section{Задачи:}

- изучить литературу по созданию флорариумов;

- определить условия для выращивания комнатных растений;

- подобрать растения для композиций;

- создать флорариумы в закрытых и открытых стеклянных емкостях;

- исследовать состояние растений в течение двух месяцев;

- определить практическое значение флорариумов.

Гипотеза: если в стеклянных предметах будут созданы подходящие условия, то растения смогут расти и развиваться в них длительное время без специального ухода.

\section{Использованные методы исследования}

\section{1. Анкетирование}

Перед тем, как приступить к созданию флорариумов, я поинтересовался у одноклассников, есть ли у них дома комнатные растения и как часто они за ними ухаживают. Также я предложил им ответить на два моих вопроса: «Могут ли комнатные цветы находиться долгое время без полива?» и «Знаете ли вы, что такое флорариум и для чего он нужен?».

\section{2. Изучение литературы}

Чтобы понять, как правильно сделать и оформить флорариумы, мне нужна была подходящая литература. Поэтому я прочитал книгу Ольги Перепеловой "Тропики в доме", которую взял в городской библиотеке, а также просмотрел специальную информацию в интернете.

\section{3. Подбор растений}


Для создания флорариумов я составил список нужных мне растений и произвел их поиск.

\section{4. Экспериментирование}

Я сделал флорариумы открытого и закрытого типов.

\section{5. Наблюдение}

Я изучал состояние растений во флорариумах на протяжении двух месяцев. Свои наблюдения каждые две недели записывал в блокнот.

\section{6. Анализ и оценка состояния растений}

После проведенных экспериментов и наблюдений, я проанализировал возможность существования цветов в стеклянных предметах и оценил полезность флорариумов.

\section{Полученные результаты и их анализ}

Я провел анкетирование, в котором приняли участие 26 человек из моего класса (табл. 1).

\section{Таблица 1}

Анкетирование одноклассников, \%

\begin{tabular}{|l|c|c|}
\hline \multicolumn{2}{|c|}{ Вопрос } & \multicolumn{2}{c|}{ Ответ } \\
\cline { 2 - 3 } & Да & Нет \\
\hline 1. Есть ли у тебя дома комнатные растения? & 77 & 23 \\
\hline 2. Могут ли цветы существовать долгое время без полива? & 2 & 98 \\
\hline 3. Знаешь ли ты, что такое флорариум и для чего он нужен? & & \\
\hline
\end{tabular}

Оказалось, что у 20 ребят (77\%) есть дома комнатные растения. Из них 15 человек занимается уходом и поливом цветов 1 раз в неделю, двое ребят ухаживают за растениями 1 раз в 2 недели, а 3 человека делают это ежедневно (диагр.1). 
Как часто проводится полив комнатных цветов дома?

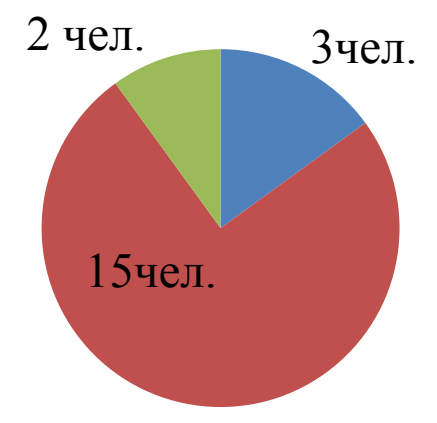

ш Ежедневно

- Раз в неделю

- Раз в 2 недели

\section{Диаграмма 1 «Уход за растениями»}

К сожалению, о существовании флорариумов знают только 7 (27\%) моих одноклассников. Большинство ребят (98\%) считают, что комнатные цветы не могут находиться длительное время без ухода и полива. Я решил доказать им обратное.

Прочитав литературу по теме исследования, я понял, что флорариумы могут быть открытого и закрытого типов. У открытого флорариума есть незакрытое отверстие. Закрытый же флорариум должен герметично закупориваться [1, с. 8]. Еще я узнал, что в закрытые флорариумы высаживают влаголюбивые цветы, а в открытые - растения, которым нужен сухой воздух.

Также я ознакомился и определился с перечнем материалов для создания различных флорариумов [2, с. 32]. Для изготовления флорариумов мне необходимы:

- стеклянные емкости различных форм и размеров;

- дренаж;

- древесный уголь;

- грунт для растений;

- комнатные растения;

- декоративные украшения.

Для своего эксперимента я решил, что буду использовать несколько видов растений, чтобы самому убедиться, какие цветы лучше высаживать в емкости. Я выбрал мох, кактусы, плющ, хлорофитум и суккуленты. Затем приступил к их 
поиску. Мох я выкопал в ближайшем лесу. Суккуленты, толстянку и кактусы приобрел в цветочном магазине, а плющ, папоротник и хлорофитум попросил у бабушки.

Для создания закрытых флорариумов я взял две стеклянные банки с крышками. На дно банок положил керамзит слоем 5 см и древесный уголь слоем 1 см, сверху насыпал почву для комнатных цветов [3, с.1]. Я решил поэкспериментировать и узнать, сможет ли кактус существовать и развиваться в условиях повышенной влажности. Поэтому в первую банку посадил кактус и влаголюбивый плющ. Во вторую же банку я высадил только влаголюбивые растения - папоротник, хлорофитум и мох. Обе емкости полил и плотно закрыл крышками. Это был единственный раз, когда растения поливались. Банки я поставил на балкон, подальше от прямых солнечных лучей, чтобы не допустить нагревания емкостей и перегрева растений.

Для создания открытого флорариума я взял круглый аквариум. В емкость положил керамзит и древесный уголь. Сверху насыпал грунт, посадил растения, любящие сухой климат - толстянку, кактус и суккулент. Затем я украсил аквариум камешками и ракушками. Флорариум полил и поставил на окно. В емкости имеется отверстие, поэтому перегрева растений быть не может.

В начале исследований в открытом флорариуме изменений я не увидел. В закрытых же сосудах в первые два дня стенки сильно запотевали. Это означало то, что я перелил цветы. Поэтому для удаления лишней влаги я снял крышки с банок и оставил их открытыми на сутки, затем банки снова закупорил. В дальнейшем капли воды на стенках появлялись только с утра, а к обеду они полностью исчезали. Значит, я добился того, чтобы в банках установилась необходимая влажность. За два месяца банки больше не открывались. Дневник моих дальнейших наблюдений представлен в таблицах 2 и 3.

Таблица 2

Дневник наблюдений. Изменения в закрытых флорариумах

\begin{tabular}{|c|c|c|c|c|c|}
\hline \multirow{2}{*}{ недели } & \multicolumn{2}{|c|}{1 банка } & \multicolumn{3}{c|}{2 банка } \\
\cline { 2 - 5 } & кактус & плющ & пох & папоротник & хлорофитум \\
\hline
\end{tabular}




\begin{tabular}{|c|c|c|}
\hline 2 & $\begin{array}{l}\text { Кактус прижился, но нет роста. } \\
\text { Плющ прижился, появился } \\
\text { первый листок. }\end{array}$ & $\begin{array}{l}\text { Мох начал активный рост. Папоротник } \\
\text { прижился, появился первый новый побег. } \\
\text { Хлорофитум прижился, начался рост } \\
\text { листьев. }\end{array}$ \\
\hline 4 & $\begin{array}{l}\text { Кактус подрос на } 3 \text { см. Плющ } \\
\text { начал рост, появились еще } 2 \\
\text { новых листика. }\end{array}$ & $\begin{array}{l}\text { Мох разрастается по банке. У } \\
\text { папоротника появились три } \\
\text { побега. Листь } \\
\text { растут. }\end{array}$ \\
\hline 6 & $\begin{array}{lcc}\text { Кактус вырос еще } & \text { на } 3 \text { см, } \\
\text { появился } & \text { новый } & \text { отросток. } \\
\text { Плющ } & \text { активно } & \text { растет, } \\
\text { появляются новые листики. } \\
\end{array}$ & $\begin{array}{l}\text { Мох разрастается по банке. Папоротник } \\
\text { активно растет, появляются новые } \\
\text { побеги. Листья хлорофитума начали } \\
\text { упираться в крышку банки. }\end{array}$ \\
\hline 8 & $\begin{array}{l}\text { Растения выглядят крепкими, } \\
\text { листья зеленые, продолжается } \\
\text { их рост. За время наблюдения } \\
\text { кактус вырос на } 9 \text { см. }\end{array}$ & $\begin{array}{l}\text { Мох занял весь объем банки. Листья } \\
\text { папоротника упираются в } \\
\text { емкости. У хлорофитума заметен бурный } \\
\text { рост листьев. У всех растений листья } \\
\text { крепкие, сочные, имеют ярко-зеленый } \\
\text { цвет. }\end{array}$ \\
\hline & \multicolumn{2}{|c|}{$\begin{array}{l}\text { Земля влажная, конденсат бывает в утреннее время, полив растений не } \\
\text { производился. }\end{array}$} \\
\hline
\end{tabular}

Таблица 3

Дневник наблюдений. Изменения в открытом флорариуме

\begin{tabular}{|c|c|c|c|}
\hline недели & толстянка & суккулент & кактус \\
\hline 2 & \multicolumn{3}{|c|}{ Цветы прижились, начали медленный рост, земля очень влажная. } \\
\hline 4 & \multicolumn{3}{|c|}{ Все растения продолжают рост, земля остается влажной. } \\
\hline 6 & \multicolumn{3}{|c|}{$\begin{array}{l}\text { У растений появились новые листики, земля сухая, произведен полив } \\
\text { растений. }\end{array}$} \\
\hline 8 & $\begin{array}{l}\text { Все растения } \\
\text { зеленый окрас. }\end{array}$ & $\begin{array}{l}\text { ооровыми } \\
\text { ся рост. } 3\end{array}$ & , крепкие, имеют \\
\hline
\end{tabular}

После проведенных исследований я выяснил, что все растения во флорариумах здоровы и активно растут [рис. 1, 2, 3]. Даже кактус, несмотря на влажный климат в закрытой емкости, хорошо себя чувствует и пускает новые отростки. У хлорофитума и папоротника я отметил бурный рост, им стало мало места в банке. Поэтому могу сделать вывод, что для флорариумов нужны медленно растущие растения. 


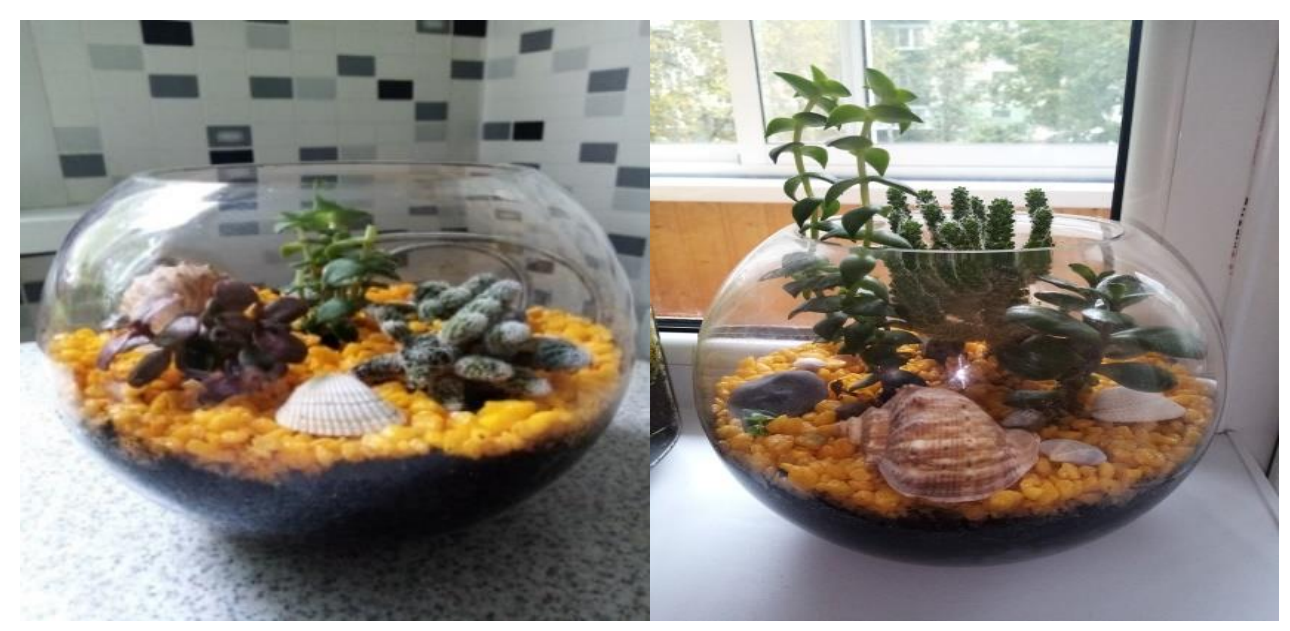

Рисунок 1

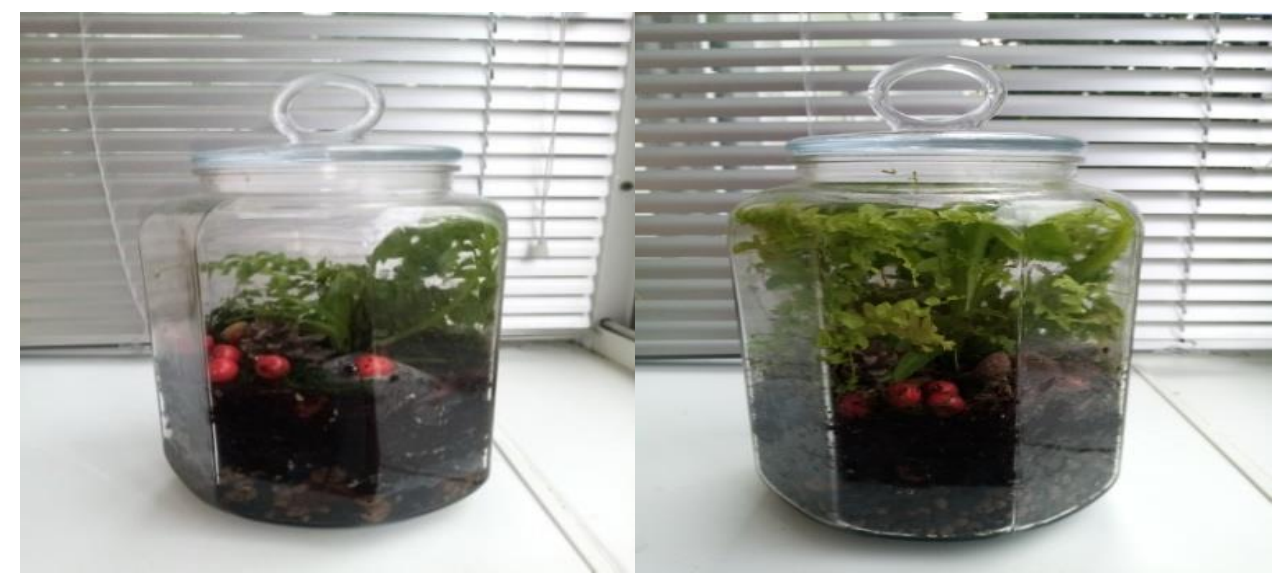

Рисунок 2

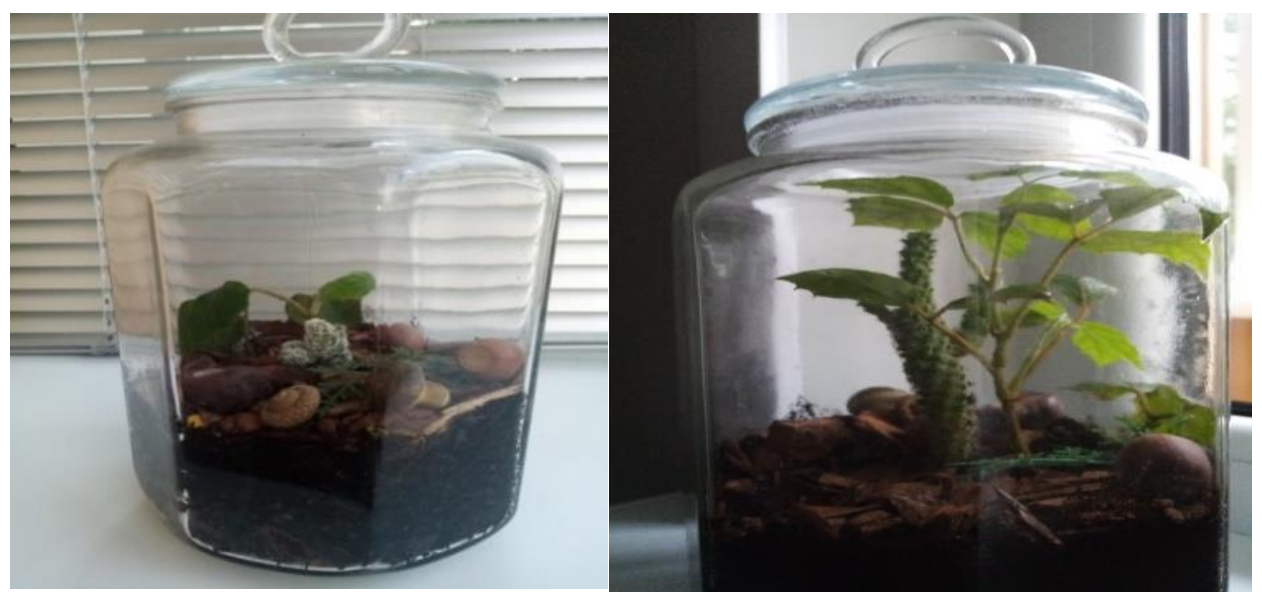

Рисунок 3

Рост и существование цветов в закрытых сосудах был возможен благодаря процессу фотосинтеза. Растения, поглощая солнечный свет, сами выделяли кислород, а ночью наоборот, потребляли его, выделяя углекислый газ. Полив же растениям не требовался, так как банки были плотно закрыты и на стенках 
образовывался конденсат, который стекал в почву и увлажнял ее. В открытом сосуде земля больше месяца была мокрой. Значит, стеклянные стенки помогают длительное время сохранять влагу в почве. За два месяца уход за растениями в закрытых емкостях отсутствовал, в открытом же сосуде полив цветов был произведен один раз. Это доказывает преимущество в использовании флорариумов по сравнению с традиционными способами выращивания комнатных растений.

\section{Заключение}

После проведенных исследований я определил положительные и отрицательные стороны существования цветов в закрытых и открытых емкостях.

К основным плюсам закрытых флорариумов можно отнести:

- отсутствие полива и специального ухода за цветами;

- можно выращивать цветы, которые боятся сквозняков и сухого воздуха;

- подходят для растений, которые любят влагу;

- отсутствуют перепады температур.

Из минусов можно выделить то, что в закрытых флорариумах корни растений могут загнивать, а также флорариумы данного типа не подходят для растений, которым нужна сухая почва.

К основным плюсам открытых флорариумов можно отнести: - редкий полив и уход за растениями;

- подходят для цветов, которым нужен сухой климат

- всегда имеется доступ к растениям и почве.

Из минусов можно выделить то, что открытые флорариумы не подходят для растений, которые боятся сквозняков.

Также я отметил полезность использования стеклянных сосудов: может быть необычным подарком, служит для украшения помещений, подходит для выращивания прихотливых растений, помогает сократить время на уход за комнатными растениями, защищает их от домашних животных и маленьких детей. Закрытый тип флорариума используется как вариант выращивания растений у людей с аллергией. 
Минусом в использовании является то, что стекло во флорариуме может лопнуть от тяжести почвы, а также разбиться при падении.

\section{Выводы}

1. Флорариумы являются доступными и интересными способами выращивания комнатных растений.

2. Флорариумы возможно сделать самостоятельно из любых прозрачных предметов.

3. Моя гипотеза подтвердилась. Действительно, если в стеклянных предметах будут созданы подходящие условия, то растения смогут расти и развиваться в них длительное время без специального ухода и полива.

Работа над созданием флорариумов мне очень понравилась и я продолжаю экспериментировать. Теперь у меня дома имеется своя коллекция, сделанная в различных стеклянных емкостях: бокале, аквариуме, полусфере и даже электрической лампочке [рис. 4] .

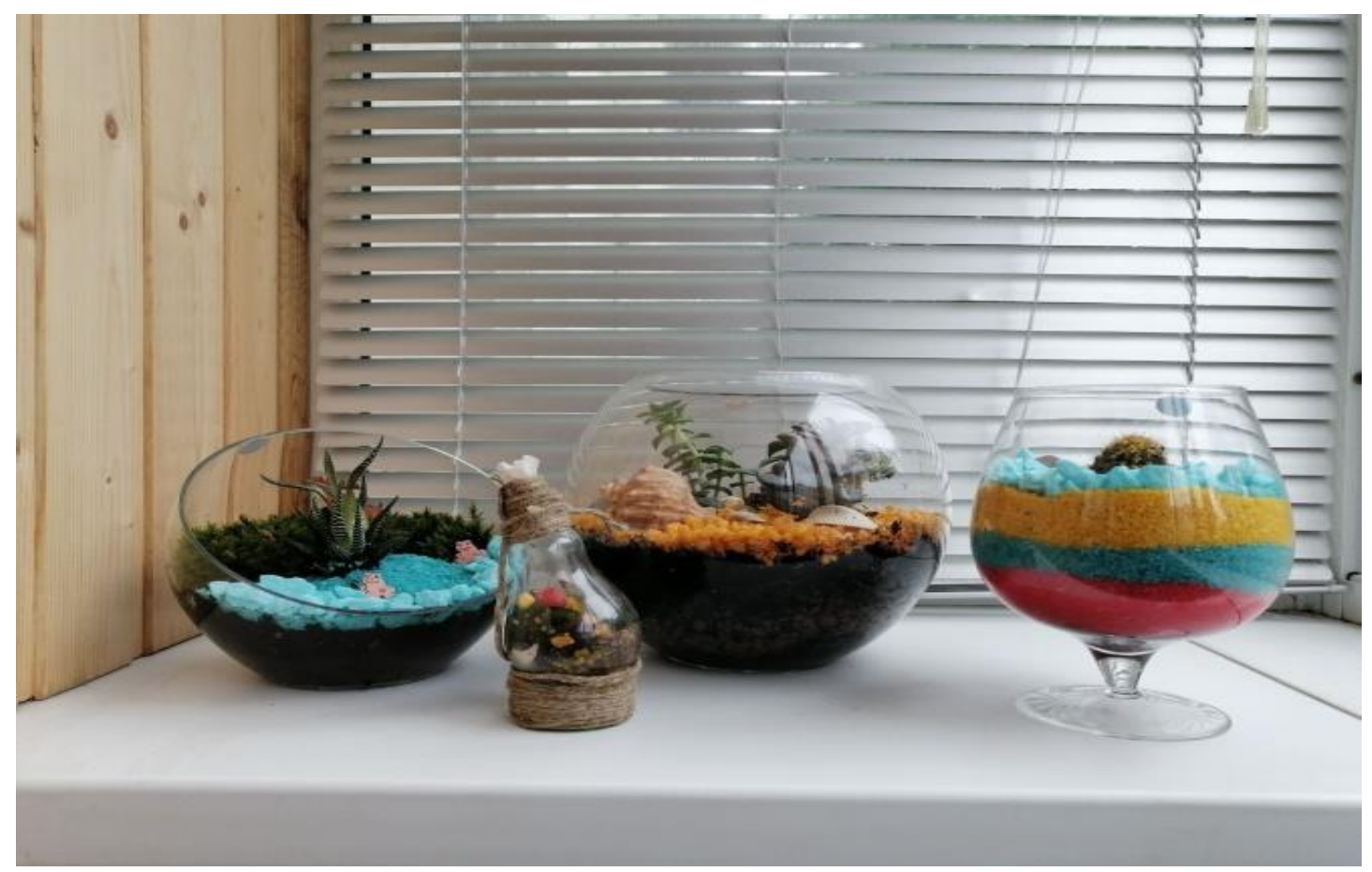

Рисунок 4 


\section{Список использованной литературы}

1. Карписонова Р.А. «Библия цветовода». Россия, издательство «АСТ» 2015г., 160c.

2. Перепелова О.В. «Флорариум. Тропики в доме». Россия, издательство «Проф-Издат», 2009г.,72с.

3. Сад в бутылке. Создай свой удивительный сад [Электронный ресурс]. Режим доступа: https://www.liveinternet.ru/users/msvet/post218173606 (дата обращения 11.04.2021). 